\section{Disorders of water balance}

Kevin Moore MRCPI,

Specialist Registrar in Endocrinology

Chris Thompson MD FRCP,

Consultant Endocrinologist

Academic Department of Endocrinology,

Beaumont Hospital, Dublin, Ireland

Peter Trainer MD FRCP, Consultant Endocrinologist, Christie Hospital,

Manchester

\section{Clin Med 2003;3:28-33}

Water homeostasis is maintained in man by balancing fluid intake, governed by the sensation of thirst, against water excretion, controlled by the antidiuretic action of the neurohypophyseal hormone arginine vasopressin (AVP) (Fig 1).

Reduction in body water leads to a rise in plasma osmolality which is detected by specialised osmotically-sensitive magnocellular neurones in the circumventricular organ (CVO). ${ }^{1}$ The CVO, which comprises the organum vasculosum lamina terminalis and the sub- fornical organ, is situated in an area of the anterior hypothalamus where fenestrations in the blood-brain barrier allow plasma access to neuronal tissue. Stimulation of the osmoreceptors in the CVO causes neural stimuli to the paraventricular nucleus (PVN) and the supraoptic nucleus (SON), the sites of vasopressin synthesis. ${ }^{2}$ From there, neural projections reach the posterior pituitary where AVP is secreted into the circulation. AVP is carried free in the bloodstream to the renal collecting duct cells. It then binds to the V-2 receptor in the basolateral membrane, activating adenyl cyclase and the generation of intracellular cyclic $\mathrm{AMP},{ }^{3}$ causing fusion of vesicles containing the aquaporin-2 water channels with the apical membrane of the collecting duct cells. This increases cell permeability to water ${ }^{4}$ and thus reduces water excretion from the kidneys.

Simultaneous with the promotion of renal water retention, stimulation of the osmoreceptors generates the sensation of thirst, which prompts an increase in fluid intake. The combination of reduced water

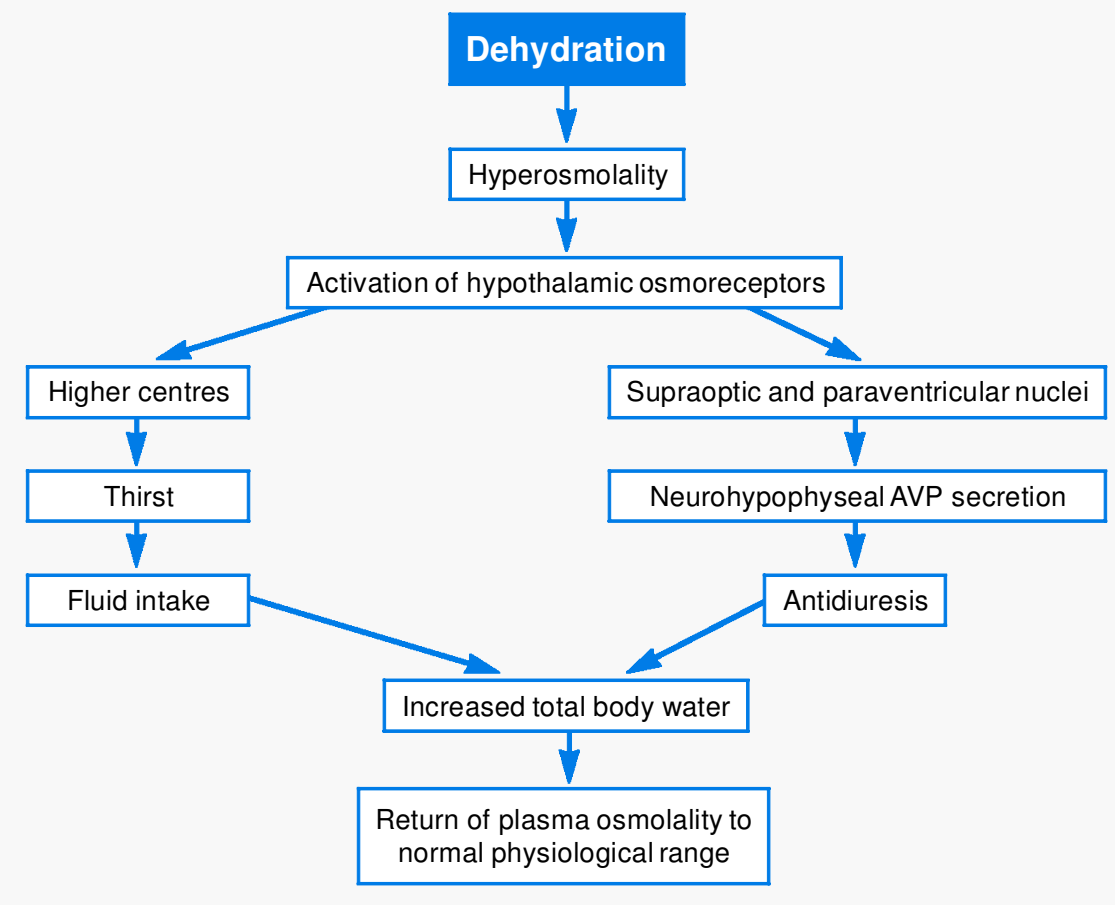

Fig 1. The physiology of water homeostasis (AVP = arginine vasopressin). loss and increased water intake returns body water and plasma osmolality to normal. As plasma osmolality falls below approximately $284 \mathrm{mOsm} / \mathrm{kg}$, AVP secretion and thirst are abolished, so that overhydration does not occur. ${ }^{5}$ The regulation of water balance is so tightly controlled in healthy people that plasma osmolality rarely changes by more than $2 \%$ of baseline in physiological conditions.

\section{Polyuric states}

Polyuria is defined as urine output greater than two litres in 24 hours, or $30 \mathrm{ml} / \mathrm{kg} / 24$ hours. There are three pathophysiologic causes of polyuria (Table 1):

- increased thirst

- decreased secretion of AVP (cranial diabetes insipidus (DI)), and

- renal resistance to AVP (nephrogenic DI).

\section{Disorders of excess thirst}

Primary disorders of thirst cause polyuria by increasing fluid intake such that plasma osmolality is lowered to below the threshold for AVP secretion, thus allowing hypotonic diuresis. They are uncommon in clinical practice, though up to $20 \%$ of patients with chronic schizophrenia have polydipsia ${ }^{6}$ often due to an irrational belief in the therapeutic benefits of ingestion of large volumes of water. The excess thirst is not usually clinically significant, though $4 \%$ of patients develop significant hyponatraemia, particularly when treated with drugs which reduce free water clearance (eg carbamazepine, phenothiazines). ${ }^{7}$ Water intoxication, leading to impaired cognitive function, seizures, permanent neurological deficits and even death, may occur.

Excess thirst also occurs in organic brain disease. Structural lesions such as trauma are more often associated with adipsia, but polydipsia has been reported with head injury. Polydipsia also occurs in patients with craniopharyngioma, particularly after extensive surgery for large tumours, when thirst excess is accompanied by other hypothalamic 
abnormalities (eg polyphagia, somnolence and sleep apnoea).

\section{Cranial diabetes insipidus}

Cranial DI is an uncommon disorder. For polyuria to become clinically apparent, $80 \%$ of AVP-secreting neurones must be destroyed. The vast majority of patients with DI have lesions of the pituitary gland or the PVN and SON, while the osmoreceptor cells in the anterior hypothalamus are unaffected and the thirst mechanism is intact. ${ }^{8}$ Polyuria is therefore accompanied by polydipsia, which is usually sufficient to replace urinary water losses. In conditions which affect the osmoreceptors, however, such as clipping of anterior communicating aneurysms, some cases of craniopharyngioma and head trauma, DI is accompanied by hypodipsia, inability to respond to hyperosmolality with appropriate water intake, and the development of serious hypernatraemia.?

Many of the early series listed idiopathic cases as the commonest cause of DI. However, in the more recent series, the increase in both the incidence of road traffic accidents and the rates of hypophysectomy have pushed these diagnoses ahead of idiopathic cases. In addition, one-third of patients categorised as having idiopathic DI have circulating antibodies to AVP-secreting cells, ${ }^{10}$ and many of them subsequently develop other autoimmune endocrine diseases, most commonly autoimmune thyroid disease. ${ }^{11}$ It is worth maintaining surveillance for the development of autoimmune endocrine disease in patients with apparent idiopathic DI. Intracranial tumours may also manifest first as apparent idiopathic DI, with magnetic resonance imaging abnormalities appearing some time after the diagnosis of AVP deficiency.

Pituitary tumours do not commonly cause DI pre-operatively, to the extent that DI in the setting of a pituitary mass would raise the differential diagnosis of craniopharyngioma or granuloma rather than adenoma. DI occurs after 10-15\% of operations for intrasellar tumours,

\section{Table 1. Classification of causes of polyuria.}

\begin{tabular}{|c|c|c|c|}
\hline \multicolumn{2}{|r|}{ A Abnormal thirst } & \multicolumn{2}{|c|}{$\begin{array}{l}\text { Idiopathic (compulsive water drinking) } \\
\text { Associated with psychosis (psychogenic polydipsia) } \\
\text { Hypothalamic disease: sarcoidosis, craniopharyngioma, trauma, } \\
\text { postencephalitis } \\
\text { Drugs: anticholinergics, tricyclic antidepressants }\end{array}$} \\
\hline B & $\begin{array}{l}\text { Cranial diabetes } \\
\text { insipidus }\end{array}$ & Secondary & $\begin{array}{l}\text { Idiopathic } \\
\text { Autoimmune/lymphocytic hypophysitis } \\
\text { Hereditary (X-linked, DIDMOAD syndrome) } \\
\text { Trauma (brain injury) } \\
\text { Tumours: pituitary, craniopharyngioma, } \\
\text { metastases, pinealoma } \\
\text { latrogenic: post-hypophysectomy or radiotherapy } \\
\text { Granulomatous/infiltrative: sarcoid, histiocytosis, } \\
\text { haemochromatosis } \\
\text { Infections: meningitis, encephalitis (particularly } \\
\text { TB), AIDS } \\
\text { Pregnancy (due to placental vasopressinase) } \\
\text { Vascular: Sheehan's syndrome, post-CABG, Gl bleed }\end{array}$ \\
\hline C & $\begin{array}{l}\text { Nephrogenic } \\
\text { diabetes } \\
\text { insipidus }\end{array}$ & $\begin{array}{l}\text { Primary } \\
\text { Secondary }\end{array}$ & $\begin{array}{l}\text { Hereditary } \\
\text { Idiopathic } \\
\text { Chronic renal disease } \\
\text { Metabolic disease: hypokalaemia, hypercalcaemia } \\
\text { Drugs: lithium, demeclocycline, AVP antagonists } \\
\text { Osmotic diuresis: glycosuria (poorly controlled } \\
\text { diabetes mellitus) } \\
\text { Systemic disease: amyloidosis, sickle-cell disease, } \\
\text { myelomatosis }\end{array}$ \\
\hline
\end{tabular}

AVP $=$ arginine vasopressin; $C A B G=$ coronary artery bypass grafting; DIDMOAD = diabetes insipidus, diabetes mellitus, optic atrophy, deafness syndrome; $\mathrm{Gl}=$ gastrointestinal; $\mathrm{TB}=$ tuberculosis.
$40 \%$ of operations for suprasellar tumours, and over $90 \%$ of operations for craniopharyngioma.

\section{Nephrogenic diabetes insipidus}

The commonest cause of nephrogenic diabetes insipidus in clinical practice is lithium therapy, with $15 \%$ of patients on chronic lithium therapy developing polyuria due to nephrogenic DI. Other metabolic causes of nephrogenic DI include hypokalaemia, hypercalcaemia and poorly controlled diabetes (Table 1).

\section{Diagnosing the polyuric patient}

The first step is to establish that the patient is genuinely polyuric. As many as $15 \%$ of patients referred for investigation of polyuria actually have normal urine volumes, with frequency of micturition due to infection, prostatism or bladder instability. If 24-hour urine volumes (which can usually be collected as outpatients) are less than 2.5 litres, no further investigations are required. If polyuria is confirmed, simple blood tests will exclude diabetes mellitus, chronic renal failure, hypokalaemia and hypercalcaemia.

\section{Water deprivation test}

The investigation of choice is the water deprivation test, a two-step test with an initial eight-hour period of water deprivation. This is followed by administration of desmopressin, a synthetic form of vasopressin modified to prolong its duration of action, rendering it suitable for clinical use and to reduce its pressor activity.

Dehydration step. Dehydration in normal physiology causes a rise in plasma osmolality, which stimulates the osmoreceptors, release of vasopressin, and subsequently a fall in urine output and thus urine concentration. Healthy individuals should demonstrate a rise in urine osmolality to more than $700 \mathrm{mOsm} / \mathrm{kg}$. Theoretically, patients with primary thirst disorders have normal physiology of vasopressin release and should respond to dehydration 
with appropriate urine concentration, whereas patients with DI, whether cranial or nephrogenic, are unable to concentrate urine. The water deprivation step can therefore distinguish between patients with DI, who fail this step, and polydipsic or normal subjects.

Desmopressin step. If urine does not concentrate, desmopressin is administered by subcutaneous or intramuscular injection. Patients with cranial DI, who do not secrete vasopressin, respond to desmopressin with appropriate urine concentration rising to over $700 \mathrm{mOsm} / \mathrm{kg}$, whereas patients with nephrogenic DI, who have renal resistance to vasopressin, remain unable to concentrate urine to more than $700 \mathrm{mOsm} / \mathrm{kg}$. The desmopressin step therefore distinguishes between cranial and nephrogenic DI.

In some cases it is unnecessary to complete the entire test. Over $80 \%$ of water deprivation tests in Beaumont Hospital are performed to establish the presence of cranial DI following hypophysectomy. The desmopressin step is unnecessary as nephrogenic DI is not an issue.

In cases of diagnostic doubt, measurement of plasma vasopressin concentrations during hypertonic saline infusion is a useful investigation.

\section{Management of polyuric states}

\section{Cranial diabetes insipidus}

Cranial DI can be conveniently managed by desmopressin. Intranasal desmopressin is rarely used now as the oral forms are easier to administer and absorption is more predictable and less affected by rhinitis or coryza. Hyponatraemia also seems less common than with the nasal preparations. Partial DI can be treated with a single nocturnal dose to prevent sleep loss due to nocturia, but complete DI requires two, three, and occasionally four, daily doses.

\section{Nephrogenic diabetes insipidus}

Nephrogenic DI is less easy to treat. Withdrawal of lithium therapy usually, but not always, leads to reversal of lithium-induced DI. Occasionally, DI can persist for years after lithium withdrawal, usually indicating that the patient has developed interstitial nephritis secondary to lithium. Thiazide diuretics reduce urine output by up to $50 \%$, and indomethacin has also been used. However, results are frequently unsatisfactory, and treatment is directed at encouraging sufficient fluid intake to replace urinary losses.

\section{Hyponatraemia}

Hyponatraemia is the commonest in-hospital electrolyte abnormality. Mild to moderate hyponatraemia (plasma sodium 126-135 $\mathrm{mmol} / \mathrm{l}$ ) and severe hyponatraemia (plasma sodium $<125 \mathrm{mmol} / \mathrm{l}$ ) occur in $14 \%$ and $1 \%$ of hospital patients, respectively. ${ }^{12}$ Hyponatraemia is usually mild and selflimiting, but severe hyponatraemia is associated with substantial morbidity ${ }^{13}$ and a 60 -fold increased mortality. ${ }^{14}$ It is usually the result of an excess of water relative to sodium, due to depletion of total body sodium or its dilution by increases in total body water. It is far more often due to a defect in water homeostasis than in sodium balance.

\section{Pseudohyponatraemia}

Pseudohyponatraemia occurs secondary to an apparent reduction in the concentration of sodium per litre of plasma when plasma is rich in lipids or proteins. A falsely low plasma sodium concentration is given when flame photometry is used to measure sodium. A true measurement is obtained with an ion-specific electrode which is less influenced than flame photometry by high plasma concentrations of lipids or proteins. ${ }^{15}$

Hyperglycaemia also causes artefactual hyponatraemia, and $10-20 \%$ of cases of hyponatraemia in hospitalised patients ${ }^{16}$ occur secondary to the hyperglycaemia of poorly controlled diabetes. The true plasma sodium level can be calculated by correcting the measured plasma sodium by approximately $1.5 \mathrm{mmol}$ for each $5 \mathrm{mmol}$ increase in plasma glucose above the normal level. ${ }^{17}$ Hyponatraemia due to hyperglycaemia does not require treatment because plasma sodium returns to normal as blood glucose control is established.

\section{Classification of hyponatraemia}

A classification of hyponatraemia for clinical purposes, linking appropriate treatment to cause, is shown in Table 2.

\section{Hypovolaemic hyponatraemia}

Hypovolaemic hyponatraemia is characterised by clinical and biochemical evidence of extracellular fluid depletion. The physiological response to this is activation of the renin-angiotensinaldosterone axis, with renal sodium conservation. Causes of gastrointestinal sodium losses are therefore associated with low urinary sodium concentration. Natriuresis points to renal sodium losses due to diuretics or, less commonly,

\section{Key Points}

Water homeostasis is maintained by the balance between fluid intake (governed by thirst) and water excretion (controlled by arginine vasopressin (AVP))

With the exception of secondary nephrogenic diabetes insipidus (DI), polyuric states caused by disorders of thirst, cranial DI and renal resistance to AVP (nephrogenic DI) are uncommon

Hyponatraemia is the commonest in-hospital electrolyte disturbance

Severe hyponatraemia carries significant morbidity and mortality; it requires accurate diagnosis and careful management depending on the patient's fluid volume status

KEY WORDS: diabetes insipidus, hypernatraemia, hyponatraemia, sodium, syndrome of inappropriate secretion of antidiuretic hormone (SIADH) 
Table 2. Classification of causes of hyponatraemia according to blood volume status.

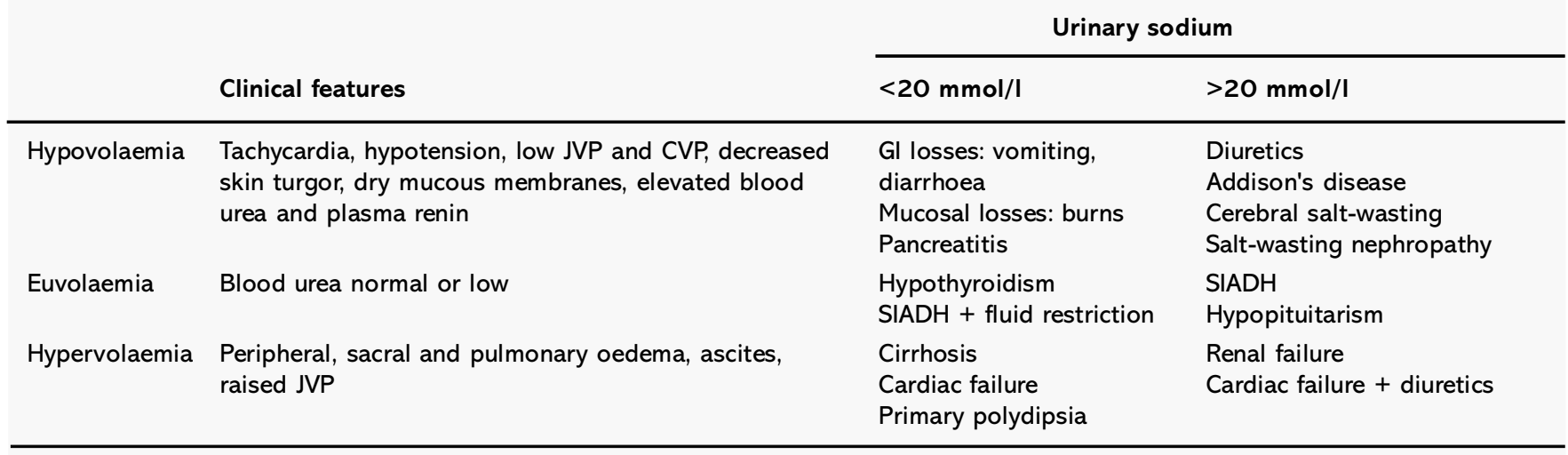

$\mathrm{CVP}=$ central venous pressure; $\mathrm{GI}=$ gastrointestinal; JVP = jugular venous pressure; SIADH = syndrome of inappropriate secretion of antidiuretic hormone.

Addison's disease, salt-losing nephropathy and cerebral salt-wasting. The commonest cause of hypovolaemic hyponatraemia is thiazide diuretic therapy.

\section{Hypervolaemic hyponatraemia}

Hypervolaemic hyponatraemia, which has a complex pathogenesis, is characterised by an excess of sodium and water, with water gain proportionately greater than sodium gain. It is associated with clinical evidence of fluid overload, including peripheral oedema, raised jugular and central venous pressures and ascites, as well as signs of the underlying disease, such as congestive cardiac failure, cirrhosis, nephrotic syndrome and acute or chronic renal failure.

\section{Euvolaemic hyponatraemia}

Euvolaemic hyponatraemia occurs in patients with hypopituitarism, hypothyroidism and the syndrome of inappropriate secretion of antidiuretic hormone (SIADH). The essential diagnostic criteria for SIADH are listed in Table $3 .{ }^{18}$ The hyponatraemia of SIADH is secondary to increased total body water with decreased total body sodium. The aetiology of SIADH is extensive (Table 4). Malignancy, pulmonary infections, central nervous system disorders and drugs, particularly carbamazepine, selective serotonin reuptake inhibitors and phenothiazines, are the commonest causes of SIADH.
Table 3. Essential diagnostic criteria for the syndrome of inappropriate secretion of antidiuretic hormone (adapted from Ref 18, with permission).

Essential diagnostic criteria

1 Plasma osmolality $<270 \mathrm{mOsm} / \mathrm{kg}$

2 Inappropriate urinary concentration (UOsm $>100 \mathrm{mOsm} / \mathrm{kg}$ )

3 Normal extracellular blood volume

4 Elevated urinary sodium ( $>40 \mathrm{mmol} / \mathrm{l})$, in presence of normal salt and water intake

5 Exclude hypothyroidism and glucocorticoid deficiency

Table 4. Aetiology of the syndrome of inappropriate secretion of antidiuretic hormone (SIADH).

$\begin{array}{ll}\text { Tumours } & \text { Bronchogenic cancer } \\ & \text { Mesothelioma } \\ & \text { Ureteric cancer } \\ & \text { Pancreatic cancer } \\ & \text { Duodenal cancer } \\ & \text { Lymphoma } \\ & \text { Endometrial cancer } \\ & \text { Leukaemia } \\ \text { Pulmonary disease } & \text { Lung abscess } \\ & \text { Empyema } \\ & \text { Pneumonia } \\ & \text { Tuberculosis } \\ & \text { Aspergillosis } \\ & \text { HIV infections } \\ & \text { Positive pressure ventilation } \\ & \text { Cerebral tumours } \\ & \text { Cerebral abscess } \\ \text { Central nervous } & \text { Hydrocephalus } \\ \text { system disorders } & \text { Subdural haematoma } \\ & \text { Subarachnoid haemorrhage } \\ & \text { Meningitis } \\ & \text { Encephalitis } \\ & \text { Phenothiazines } \\ & \text { Tricyclic antidepressants } \\ \text { Chlorpropamide } & \text { Ecstasy } \\ & \text { Carbamazepine } \\ \text { Cyclophosphamide } \\ \text { Selective serotonin reuptake inhibitors }\end{array}$




\section{Cerebral salt-wasting}

Hyponatraemia in the setting of traumatic brain injury or cranial surgery is often assumed incorrectly to be due to SIADH, but the diagnosis of cerebral salt-wasting should be considered if there is clinical and biochemical evidence of hypovolaemia (raised blood urea, hypotension, tachycardia) with diuresis and natriuresis. It is thought that natriuretic peptides, released by an undefined mechanism in response to cerebral insults, cause the natriuresis and diuresis, leading to hypovolaemia and hyponatraemia.

Cerebral salt-wasting can be differentiated from SIADH by the evidence of hypovolaemia and the marked diuresis. ${ }^{19}$ Misdiagnosis as SIADH is a serious error because the fluid restriction which would be imposed for SIADH would worsen the hypovolaemia. Treatment of cerebral salt-wasting needs intravenous saline, often in large doses. ${ }^{19}$

\section{Clinical manifestations of hyponatraemia}

The symptoms and signs of hyponatraemia depend on the plasma sodium concentration and the rapidity of the fall in plasma sodium (Table 5 ). Rapid rates of fall are associated with cerebral oedema and are more likely to lead to the development of neurological sequelae. In chronic hyponatraemia, adaptation to the low plasma osmolality occurs which prevents the development of cerebral oedema. Urgent correction is not therefore necessary in most cases of chronic hyponatraemia (see below). Symptoms and sequelae of hyponatraemia are also more likely in the presence of coexistent abnormalities, such as structural cerebral lesions, hypoxia, hypercalcaemia and hypokalaemia. Neurological symptoms are therefore likely, for instance, in a patient with SIADH secondary to subdural haematoma who is hypoxic and dehydrated, even if the ambient hyponatraemia is mild.

\section{Assessment of the hyponatraemic patient}

Assessment is directed towards identifying signs of underlying illnesses, such as Addison's disease, hypopituitarism and hypothyroidism, and calculating the extracellular fluid volume status of the patient. Signs of volume depletion, such as tachycardia, postural hypotension and decreased skin turgor, are particularly important. The most useful laboratory investigation is urinary sodium concentration which defines the source of sodium loss (Table 2). Measurement of plasma vasopressin is of little value in the differential diagnosis of hyponatraemia, as the plasma concentrations are elevated in over $90 \%$ of cases, irrespective of the aetiology.

\section{Management of the hyponatraemic patient}

The underlying aetiology of the hyponatraemia determines the management.

\section{Hypovolaemic hyponatraemia}

Replacement of sodium and water is required in hypovolaemic natraemia, usually with intravenous sodium chloride solution, and treatment of the underlying disorder.

\section{Hypervolaemic hyponatraemia}

Treatment of hypervolaemic hyponatraemia is often difficult because of the severity and complexity of the underlying disease process. Diuretic therapy is almost always required and occasionally also fluid restriction.

\section{Euvolaemic hyponatraemia}

In chronic asymptomatic euvolaemic hyponatraemia, the treatment of choice is fluid restriction, with intake limited to 800-1,200 $\mathrm{ml}$ of fluid per day, according to the severity of the hyponatraemia. If fluid restriction alone does not restore normonatraemia, demeclocycline can be used. This drug inhibits the action of vasopressin on the distal collecting tubule of the kidney and induces nephrogenic DI. Demeclocycline can take up to four days to work; side effects, including photosensitivity and nephrotoxicity, can complicate treatment.

Vasopressin antagonists may be more effective than demeclocycline in treating SIADH. ${ }^{20}$ Clinical trials are continuing, and these drugs are not yet universally available for clinical use. Intravenous sodium chloride solution can also be used in the treatment of euvolaemic hyponatraemia, and studies have shown that a 2-litre infusion of isotonic saline increased plasma sodium concentration in those patients with SIADH who presented with urine osmolality below $538 \mathrm{mOsm} / \mathrm{kg}$, without recorded detrimental effects. ${ }^{21}$

\section{Uncertain classification}

In cases where the classification of hyponatraemia is difficult, cautious intravenous saline therapy is recommended as first-line treatment, on the basis that there is likely to be some benefit from fluids in euvolaemic hyponatraemia whereas hypovolaemic hyponatraemia will be worsened by ill-judged fluid restriction. Clearly, however, hypervolaemic hyponatraemia should first be excluded.

\section{Chronic symptomatic hyponatraemia}

Patients with chronic symptomatic hyponatraemia are at high risk of central pontine myelinosis (CPM), characterised clinically by a spastic quadriparesis and

Table 5. Symptoms and signs of hyponatraemia.

\section{Plasma sodium concentration Symptoms and signs}

\author{
Usually asymptomatic \\ Anorexia, nausea, vomiting, abdominal cramps, \\ disorientation, headaches \\ Agitation, confusion, hallucinations, impaired mental \\ function, incontinence \\ Seizures, coma
}


pseudobulbar palsy, if rapid correction of the plasma sodium occurs. ${ }^{22}$ Patients may develop a 'locked in state', typified by lethargy, behavioural changes and alterations in cognition. Myelinosis is extrapontine in $10 \%$ of cases and presents as ataxia, irregular behaviour or movement disorders such as dystonia or parkinsonism. The symptoms of myelinosis occur 2-3 days after correction of the hyponatraemia, with variable prognosis. Persistent neurological deficits, usually bulbar dysfunction and spastic quadriparesis, are common. ${ }^{23}$

\section{Acute symptomatic hyponatraemia}

Acute symptomatic hyponatraemia, with seizures and altered consciousness, is a medical emergency with high risk of cerebral herniation and death. Prompt treatment to prevent cerebral oedema is indicated, with hypertonic saline (3\%) infused at a rate to increase the plasma sodium by $1 \mathrm{mmol} /$ litre/hour. The risk of CPM is less in the reversal of acute hyponatraemia than in the treatment of chronic hyponatraemia, but precautions should be observed. The infusion of saline should be stopped when the patient becomes asymptomatic, regardless of the degree of hyponatraemia. The rate of change of plasma sodium should be less than $12 \mathrm{mmol}$ over 24 hours $^{22,24}$ and should not exceed $25 \mathrm{mmol}$ over 48 hours. $^{25}$ Regular measurement of plasma electrolytes at two-hourly intervals is important so that the infusion can be stopped or the rate adjusted, where appropriate.

\section{References}

1 Thrasher TN. Circumventricular organs, thirst and vasopressin secretion. In: Schrier R (ed). Vasopressin. New York: Raven Press, 1985:311-8.

2 Oliet SH, Bourqe CW. Mechanosensitive channels transduce osmosensitivity in supraoptic neurons. Nature 1993;364: 341-3.

3 Knepper MA, Nielsen S, Chou CL, DiGiovanni SR. Mechanism of vasopressin action in the renal collecting duct. Review. Semin Nephrol 1994;14:302-21.

4 Nielsen S, Agre P. The aquaporin family of water channels in kidney: an update on physiology and pathophysiology of aqua- porin-2. Review. Kidney Int 1996;49: 1718-23.

5 Thompson CJ, Bland J, Burd J, Baylis PH. The osmotic thresholds for thirst and vasopressin release are similar in healthy man. Clin Sci (Lond) 1986;71:651-6.

6 de Leon J, Verghese C, Tracy JI, Josiassen RC, Simpson GM. Polydipsia and water intoxication in psychiatric patients: a review of the epidemiological literature. Review. Biol Psychiatry 1994;35:408-19.

7 Illowsky BP, Kirsch DG. Polydipsia and hyponatremia in psychiatric patients. Review. Am J Psychiatry 1988;145:675-83.

8 Thompson CJ, Baylis PH. Thirst in diabetes insipidus: clinical relevance of quantitative assessment. QJM 1987;246:853-62.

9 Smith D, McKenna K, Moore K, Tormey W et al. Baroregulation of vasopressin release in adipsic diabetes insipidus. J Clin Endocrinol Metabol 2002;87:4564-8.

10 Scherbaum WA, Bottazzo GF. Autoantibodies to vasopressin cells in idiopathic diabetes insipidus: evidence for an autoimmune variant. Lancet 1983;i:897-901.

11 Scherbaum WA, Wass JA, Besser GM, Bottazzo GF, Doniach D. Autoimmune cranial diabetes insipidus; its association with other endocrine diseases and with histiocytosis X. Clin Endocrinol (Oxf) 1986;25: 411-20.

12 Flear CT, Gill GV, Burn J. Hyponatraemia: mechanisms and management. Lancet 1981;ii:26-31.

13 Arieff AI. Hyponatremia, convulsions, respiratory arrest, and permanent brain damage after elective surgery in healthy women. N Engl J Med 1986;314:1529-35.

14 Anderson RJ. Hospital-associated hyponatremia. Kidney Int 1986;29:1237-47.

15 Ladenson JH, Apple FS, Koch DD. Misleading hyponatremia due to hyperlipemia: a method dependent error. Ann Intern Med 1981;95:707-8.

16 Anderson RJ, Chung HM, Kluge R, Schrier RW. Hyponatremia: a prospective analysis of its epidemiology and the pathogenetic role of vasopressin. Ann Intern Med 1985; 102:164-8.

17 Katz MA. Hyperglycemia-induced hyponatremia - calculation of expected serum sodium depression. N Engl J Med 1973; 289: 843-4.

18 Verbalis JG. Hyponatremia. Review. Baillières Clin Endocrinol Metabol 1989; 3:499-530.

19 Smith DM, McKenna K, Thompson CJ. Hyponatraemia. Review. Clin Endocrinol (Oxf) 2000;52:667-78.

20 Saito T, Ishikawa S, Abe K, Kamoi K et al. Acute aquaresis by the nonpeptide vasopressin (AVP) antagonist OPC-31260 improves hyponatremia in patients with syndrome of inappropriate secretion of antidiuretic hormone (SIADH). J Clin Endocrinol Metab 1997;82:1054-7.

21 Musch W, Decaux G. Treating the syndrome of inappropriate ADH secretion with isotonic saline. QJM 1998;91:749-53.

22 Cluitmans FH, Meinders A. Management of severe hyponatremia: rapid or slow correction. Review. Am J Med 1990;88:161-6.

23 Karp BI, Laureno R. Pontine and extrapontine myelinolysis: a neurologic disorder following rapid correction of hyponatremia. Medicine (Baltimore) 1993;72:359-73.

24 Sterns RH, Baer J, Ebersol S, Thomas D et al. Organic osmolytes in acute hyponatremia. Am J Physiol 1993;264:F833-6.

25 Verbalis JG, Martinez AJ. Neurological and neuropathological sequelae of correction of chronic hyponatremia. Kidney Int 1991;39: 1274-82. 